\title{
Drug utilization study of antipsychotics among schizophrenia patients in a tertiary care teaching hospital: a retrospective observational study
}

\author{
Sahana M. Mogali, Basavaraj C. Kotinatot*
}

Department of Pharmacology, BIMS, Belagavi, Karnataka, India

\author{
Received: 20 March 2020 \\ Accepted: 10 April 2020 \\ *Correspondence: \\ Dr. Basavaraj C. Kotinatot, \\ Email: drbckotinatot@gmail.com
}

Copyright: (C) the author(s), publisher and licensee Medip Academy. This is an open-access article distributed under the terms of the Creative Commons Attribution Non-Commercial License, which permits unrestricted non-commercial use, distribution, and reproduction in any medium, provided the original work is properly cited.

\begin{abstract}
Background: Aim of the study was to evaluate the drug utilization pattern of antipsychotics in schizophrenia patients in a tertiary care hospital.

Methods: A retrospective observational study was conducted over a period of one year. Demographic data and drug utilization pattern of antipsychotics was collected from the surveyed prescriptions. Using WHO prescribing indicators data was analysed. Results were expressed in percentage.

Results: Out of 300 prescriptions analysed, males were $58 \%$ and females $42 \%$. Majority of schizophrenia patients were in age group of 15 to 45 years $70.33 \%$. Olanzapine $75 \%$ was most common antipsychotic drug prescribed followed by risperidone $10.7 \%$. Haloperidol $9.6 \%$, fluphenazine $3.7 \%$ and chlorpromazine $1 \%$ were the other antipsychotics prescribed. Atypical antipsychotics $85.7 \%$ were commonly prescribed than conventional ones $4.3 \%$. Concomitant drugs prescribed were anticholinergics, antihistaminics, sedative-hypnotics, antidepressants, mood stabilizers, antiulcer drugs and vitamin B complexes. Average number of drugs prescribed per prescription 3.26.

Conclusions: Nowadays atypical antipsychotics are preferred over conventional ones because of their less side effects. Drug utilization study helps in rational usage of drugs important for patient care.
\end{abstract}

Keywords: Antipsychotics, Schizophrenia, Olanzapine

\section{INTRODUCTION}

According to world health organization (WHO) schizophrenia is a chronic mental disorder characterized by distortions in thinking, perception, emotions, language, sense of self and behaviour. It usually starts in late adolescence or early childhood. About 20 million people are affected worldwide and its prevalence in India is 4.3 to 8.7 million. $^{1,2}$

Most common positive symptoms of schizophrenia are lack of insight, auditory hallucinations, ideas of reference, delusion of persecution, flatness of affect and thought alienation. Negative symptoms include social withdrawal, self-neglect, loss of motivation, emotional blunting and paucity of speech. ${ }^{3}$

Medications and psychological support that includes cognitive behaviour therapy are effective treatment. The first line drug for a patient with first episode of psychosis is an oral atypical antipsychotic like risperidone or olanzapine. ${ }^{3}$ First generation or typical antipsychotics are associated with extrapyramidal side effects (EPS), sedation, hyperprolactinemia, postural hypotension, neuroleptic malignant syndrome, anticholinergic effects and reduced seizure threshold. Second generation or atypical antipsychotics less frequently induce extrapyramidal side effects and are helpful in improving 
the negative symptoms, hence preferred over conventional drugs.

WHO defines drug utilization study as the marketing, distribution, prescription and uses of drugs in a society with special emphasis on the resulting medical, social and economical consequences. ${ }^{4}$ It facilitates the rational usage of drugs. With the knowledge of prescription pattern study, the necessary measures required in improving the prescribing habits of physicians can be made.

Therefore, this study is undertaken to evaluate the drug utilization pattern of antipsychotics in schizophrenia patients in this tertiary care hospital.

\section{METHODS}

After obtaining approval from Institutional Ethics Committee this retrospective observational study was carried out over a period of one year from January to December 2019 in outpatient department of psychiatry at Belagavi Institute of Medical Sciences, Belagavi, a tertiary care hospital.

Prescriptions of schizophrenia patients who were on antipsychotics of all age group and either sex with or without comorbid condition were included in this study. Those prescriptions with insufficient data were excluded.

The demographic data and drug utilization pattern of antipsychotics was collected from the surveyed prescriptions. Analysis of data was done by using WHO prescribing indicators. ${ }^{5,6}$ Results were analysed statistically and expressed in percentage using SPSS 19.0 (IBM Corp., NY, USA).

\section{RESULTS}

Total number of prescriptions which fulfilled the criteria were 300 out of which males were $58 \%$ and females were $42 \%$ as shown in (Figure 1). Majority of schizophrenia patients were in the age group of 15 to 45 years $70.33 \%$ shown in (Table 1).

Olanzapine $75 \%$ was the most common antipsychotic drug prescribed followed by risperidone $10.7 \%$. Haloperidol 9.6\%, fluphenazine $3.7 \%$ and chlorpromazine $1 \%$ were the other antipsychotics prescribed as shown in (Table 2).

Second generation or atypical antipsychotics $85.7 \%$ were commonly prescribed than the first generation or typical ones $4.3 \%$ as shown in (Figure 2).

Concomitant drugs prescribed were anticholinergics, antihistaminics, sedative-hypnotics, antidepressants, mood stabilizers, antiulcer drugs and vitamin $B$ complexes.
Among anticholinergics trihexyphenidyl was the most common drug prescribed $40 \%$. Sedative-hypnotics like lorazepam, diazepam, alprazolam and injection chlordiazepoxide were prescribed in $18.3 \%$ patients for anxiety relief.

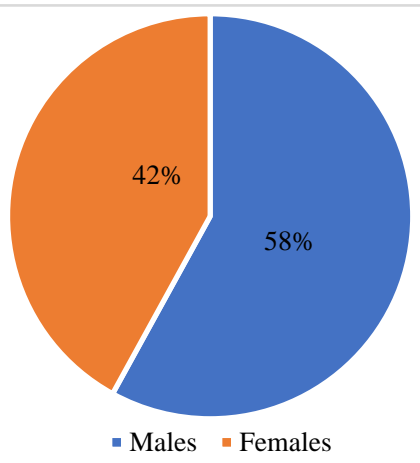

Figure 1: Sex wise distribution of patients.

Table 1: Age wise distribution of patients.

\begin{tabular}{|ll|}
\hline Age in years & Number of patients $(\%)$ \\
\hline$<\mathbf{1 5}$ & $1(0.33)$ \\
\hline $\mathbf{1 5 - 4 5}$ & $211(70.33)$ \\
\hline $\mathbf{4 6 - 6 0}$ & $76(25.33)$ \\
\hline$>\mathbf{6 0}$ & $12(4)$ \\
\hline
\end{tabular}

Table 2: Antipsychotics prescribed to schizophrenia cases.

\begin{tabular}{|ll|}
\hline $\begin{array}{l}\text { Antipsychotics } \\
\text { prescribed }\end{array}$ & Number of patients $(\%)$ \\
\hline Olanzapine & $225(75)$ \\
\hline Risperidone & $32(10.7)$ \\
\hline Haloperidol & $11(3.7)$ \\
\hline Fluphenazine & $29(9.6)$ \\
\hline Chlorpromazine & $3(1)$ \\
\hline
\end{tabular}

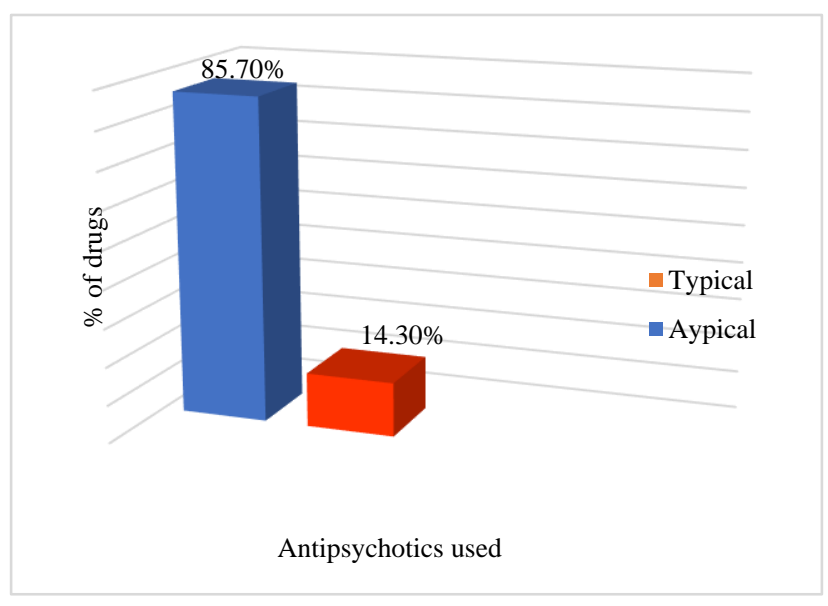

Figure 2: Types of anti-psychotics used. 
Antihistaminic like injection promethazine 6\% was combined with injection haloperidol in aggressive cases for rapid control of agitation. Mood stabilizer like sodium valproate was rarely prescribed 3\%. Among antidepressant, selective serotonin reuptake inhibitors (SSRI) like fluoxetine $2.6 \%$ was commonly used antiulcer drugs like ranitidine ( $\mathrm{H} 2$ receptor blocker) and omeprazole (proton pump inhibitor) were prescribed in $67 \%$ of cases. Vitamin B complexes tablets were prescribed in almost $89 \%$ cases as shown in (Figure 3).

Table 3: Analysis as per the WHO prescribing indicators.

\begin{tabular}{|l|l|}
\hline Variables & $\%$ \\
\hline $\begin{array}{l}\text { Average number of drugs per } \\
\text { prescription }\end{array}$ & 3.26 \\
\hline $\begin{array}{l}\text { Percentage of antipsychotic drugs } \\
\text { prescribed by generic name }\end{array}$ & 96 \\
\hline $\begin{array}{l}\text { Percentage of fixed-dose combinations } \\
\text { of antipsychotics }\end{array}$ & 6 \\
\hline Percentage of injectables prescribed & 6.2 \\
\hline $\begin{array}{l}\text { Percentage of antipsychotic drugs } \\
\text { prescribed from national list of essential } \\
\text { medicines (NLEM) }\end{array}$ & 85.6 \\
\hline
\end{tabular}

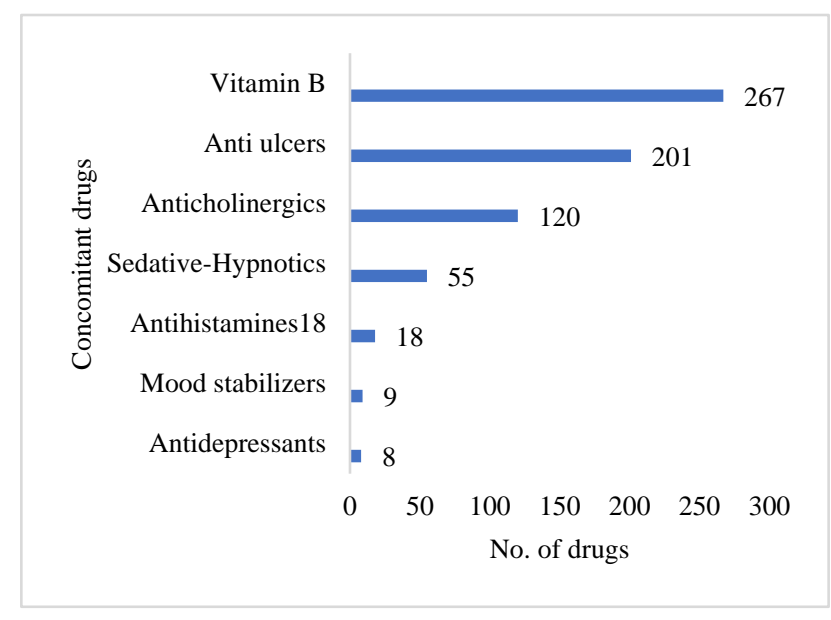

Figure 3: Concomitant drugs used in schizophrenia patients.

\section{DISCUSSION}

In our study antipsychotics were most commonly prescribed to males $58 \%$ and the most common age group affected was 15 to 45 years $70.3 \%$. Similar findings were seen in a study that showed antipsychotic prescribing was greater in males between 25 to 55 years. ${ }^{7}$ A multicentric study, conducted by Chong et al showed male predominance $55.9 \%$ and also in a study by Banerjee et al $78.6 \%$ of schizophrenics were less than 40 years. ${ }^{8,9}$

Most common antipsychotic drug prescribed in this study was olanzapine $75 \%$ followed by risperidone $10.7 \%$. This is due to availability of these drugs at our hospital. Atypical antipsychotics were commonly used because of their advantages over conventional drugs and also, they tend to improve the impaired cognitive functions of psychotics. Our findings were consistent with results seen in a study by Paul et al where olanzapine $51.04 \%$ was most commonly prescribed followed by risperidone $17.14 \% .^{10}$ Similar observations were also seen in studies by Siddiqui et al and Atal et al. ${ }^{11,12}$

Among the concomitant drugs used trihexyphenidyl was the most commonly prescribed drug. It is an anticholinergic, used to counteract EPS secondary to antipsychotic drugs. Anti-cholinergic side effects like retention of urine, constipation and dry mouth are common. Many studies have shown that the addition of anticholinergic medication can exacerbate existing tardive dyskinesia. ${ }^{13}$ The 2009 schizophrenia patient outcomes research team treatment recommendations stated that 'the prophylactic use of anticholinergic drugs to reduce the incidence of EPS was not warranted in patients treated with second generation, but should be evaluated on an individual basis for patients treated with first generation antipsychotics. ${ }^{14}$

Sedative-hypnotics like benzodiazepines were next commonly used drugs. Their long-term use can cause memory impairment, depression, tolerance, and dependence. Some guidelines recommend their use should be limited for short term (maximum of four weeks) or minimum effective doses given for intermittent duration. ${ }^{15}$

In our study the total number of drugs prescribed were 978. The average number of drugs per prescription was 3.26. Study conducted by Rode et al and Thakkar showed the average drug per prescription 2.1 and 1.7 respectively. Thus, our study showed a higher value than these. ${ }^{16,17}$

$96 \%$ of antipsychotics were prescribed with generic names in our study. This is because our tertiary care centre is a government hospital and also these are cost effective drugs. George at el also reported a high use of generic drugs $98.15 \% .{ }^{18}$ Among all the antipsychotics prescribed in our study $85.6 \%$ were from national list of essential medicines (NLEM). This was in contrast to the findings seen in study by Patted where only $47.3 \%$ patients received drugs from NLEM. ${ }^{19}$

In this study $6.2 \%$ of injectables were prescribed. Depot preparation of fluphenazine decanoate was given in $3.7 \%$ of uncooperative patients.

\section{CONCLUSION}

In our study we noted that there is increasing trend in prescribing atypical antipsychotics over conventional ones. It was observed that the adherence of prescription pattern to WHO indicators was met as most of the drugs were prescribed by their generic names and were included from NLEM. Inappropriate use of drugs can 
cause increased cost of patient care, adverse effects, morbidity and mortality. Thus, proper evaluation of prescriptions helps in providing a good health care to the population.

\section{Limitations}

As it was a retrospective observational study, we could not monitor the compliance with prescribed antipsychotics. Hence there is further need for a prospective study to assess the compliance of patients and to study the adverse drug reactions.

\section{ACKNOWLEDGEMENTS}

Authors would like to thank their director of the institution, head of the department of psychiatry and staff of the pharmacology department for their support.

\section{Funding: No funding sources}

Conflict of interest: None declared

Ethical approval: The study was approved by the Institutional Ethics Committee

\section{REFERENCES}

1. GBD 2017 Disease and injury incidence and prevalence collaborators. Global, regional and national incidence, prevalence and years lived with disability for 354 diseases and injuries for 195 countries and territories, 1990-2017: a systematic analysis for the Global Burden of Disease Study 2017. Lancet. 2018;636(18):32279-7.

2. Schizophrenia facts and statistics. 2017. Available at: http://www.schizophrenia.com/szfacts.htm. Accessed on 4 January 2020.

3. Picchioni MM, Murray MR. Schizophrenia, Clinical review. BMJ. 2007;335:91-5.

4. Introduction to Drug Utilization Research by World Health Organization. Available at: http://www. whocc.no/filearchive/publications/drug-utilizationresearch.pdf. Accessed on 4 January 2020.

5. WHO. How to investigate drug use in health facilities: selected drug use indicators - EDM research series No. 007. 1993. Available at: http://apps.who.int/medicinedocs/en/d/Js2289e. Accessed on 4 January 2020.

6. National list of Essential Medicine. 2015. Available at:http://cdsco.nic.in/WriteReadData/NLEM2015/NL EM,\%202015.pdf. Accessed on 4 January 2020.

7. Hollingworth SA, Siskind DJ, Nissen LM, Robinson M, Hall WD. Patterns of antipsychotic medicine use in Australia 2002-2007. Aust NZJ Psychiatry. 2010;44:372-7.

8. Chong MY, Tan CH, Fujii S, Ungyari GS, Si T, Chung EK, et al. Antipsychotic drug prescription for schizophrenia in East Asia: rationale for change. Psychiatr Clin Neurosci. 2004;58(1):61-7.
9. Banerjee I, Roy B, Sathian B, Banerjee I, Chakraborthy PK, Saha A. Sociodemographic profile and utilization pattern of antipsychotic drugs among schizophrenic inpatients: a cross sectional study from western region of Nepal. BMC Psychiatry. 2013;13:96.

10. Paul PK, Konwar M, Das S. To study the prescribing pattern of antipsychotic drugs in a tertiary care hospital of Assam. Int $\mathbf{J}$ Pharm Pharm Sci. 2014;6(4):435-7.

11. Siddiqui RA, Shende TR, Mahajan HM, Borkar A. Antipsychotic medication prescribing trends in a tertiary care hospital. Int J Basic Clin Pharmacol. 2017;5(4):1417-20.

12. Atal S, Atal S. Drug prescribing pattern and cost analysis of antipsychotics at a tertiary care hospital. Int J Pharm Sci Res. 2016;7(6):2611-4.

13. Kane J. Tardive Dyskinesia: Epidemiological and Clinical Presentation. In: Davis KL, Charney D, Coyle JT, Nemeroff C, editors. Neuropsychopharmacology -5 th Generation of Progress. Philadelphia, Pennsylvania: Lippincott, Williams, and Wilkins; 2002.

14. Buchanan RW, Kreyenbhul J, Kelley DL. The 2009 schizophrenia PORT psychopharmacological treatment recommendations and summary statements. Schizophr Bull. 2010;36:71-93.

15. Ashton H. Guidelines for the rational use of benzodiazepines. When and what to use. Drugs 1994;48(1):25-40.

16. Rode SB, Ajagallay RK, Salankar HV, Sinha U. A study on drug prescribing pattern in psychiatry outpatient department from a tertiary care teaching hospital. Int J Basic Clin Pharmacol. 2014;3(3):51722.

17. Thakkar KB, Jain MM, Billa G, Joshi A, Khobragade AA. A drug utilization study of psychotropic drugs prescribed in the psychiatry outpatient department of a tertiary care hospital. J Clinic Diag Res. 2013;7(12):2759-64.

18. George A, Chaithra S, Thomas JE, James A, Kumar ST. Study on prescribing pattern in psychiatric disorders in a tertiary care hospital. Int $\mathbf{J}$ Innovative Pharm Sci Res. 2016;4(6):641-7.

19. Patted UH, Hema NG, Nagaraj AKM. Antipsychotics in schizophrenia: a retrospective study of drug utilization pattern in outpatient department of psychiatry at a tertiary care hospital. Int J Basic Clin Pharmacol. 2018;7:167-2.

Cite this article as: Mogali SM, Kotinatot BC. Drug utilization study of antipsychotics among schizophrenia patients in a tertiary care teaching hospital: a retrospective observational study. Int J Basic Clin Pharmacol 2020;9:971-4. 